\title{
Н.Л. ФРОЛОВА
}

\section{НЕТИПИЧНЫЕ \\ ОРГАНИЗАЦИОННО- ТВОРЧЕСКИЕ ФОРМЫ РОССИЙСКОГО РЕПЕРТУАРНОГО ТЕАТРА В 2000-е ГОДЫ}

\author{
Надежда Леоновна Фролова, \\ Российский институт театрального искусства (ГИТИС), \\ продюсерский фракультет, \\ кафедра продюсерства и менеджмента \\ исполнительских искусств, \\ аспирант, \\ Малый Кисловский пер., д. 6 , \\ Москва, 125009, Россия \\ E-mail: frolova.gitis@gmail.com
}

Реферат. В статье рассматриваются появившиеся на рубеже XX-XXI вв. и нехарактерные для российской практики организационно-творческие формы репертуарного театра - театральные конгломераты, объединяющие несколько театральных коллективов разнообразных художественных направлений, и театры без труппы, которые, объявляя себя проектными, тем не менее тяготеют к репертуарной модели. В статье приводится аргументация отнесения театров без труппы к театрам репертуарного типа, что может составить научную новизну работы.

Процесс функционирования нетрадиционных организационно-творческих форм исследуется во взаимосвязи с развитием современного языка театрального искусства, в чем заключается актуальность представленного текста. Материалом для изучения послужила деятельность театров Москвы и Санкт-Петербурга: «Балтийского дома», «Особняка», «Практики», «Приюта комедианта», «Театра. dос», Театра Наций, Центра драматургии и режиссуры $и$ «Школы драматического искусства».

Также анализируется взаимодействие традиционных и альтернативных форм деятельности репер- туарного театра и производится сравнение с зарубежными репертуарными моделями.

Ключевые слова: А. Васильев, документальность, МХТ, перформативность, постоянная труппа, проектный театр, репертуарный театр, театры без труппы.

Для цитирования: Фролова Н.Л. Нетипичные организационно-творческие формы российского репертуарного театра в 2000-е годы // Обсерватория культуры. 2016. Т. 13, № 3. С. $321-328$.

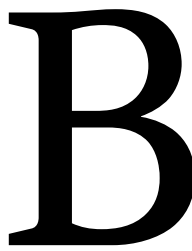

истории искусства рубеж веков - время, характеризующееся поисками новых идей, концепций и путей развития сложившихся институций. Рубеж XX и XXI вв. не стал исключением для российского театрального искусства. Как известно, уже в 1980-х гг. деятели театра заговорили о необходимости реформы существующей театральной системы. В 1990-е гг. дискуссии о судьбе репертуарного театра становились все острее и затрагивали множество болезненных вопросов. Среди них - и разрушение института художественных руководителей, и утрачиваемая связь театра с пульсом современности, и критически медленная обновляемость трупп, и сокращение зрительской аудитории, и многие другие.

Проблемы организационного характера сопрягались с ощущением творческого тупика и исчерпанности традиций. Процесс поиска новых форм в театральном искусстве оказался тесно связан с апробацией таковых в театральном деле.

Практических решений насущных проблем (от обновляемости труппы до воспроизводства театраль- 


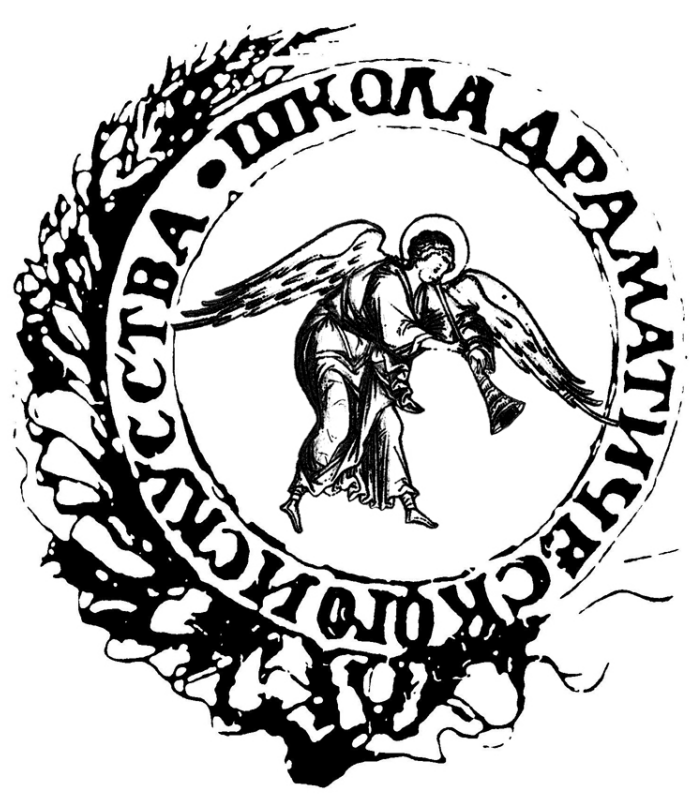

ной публики) было предложено немало, и большинство из них - деятелями, чье профессиональное сознание формировалось внутри системы репертуарного театра. Процесс интенсивного внедрения в российское театральное пространство изменений развивался благодаря «инициативе снизу», что свидетельствует о реальной способности сложившейся в России театральной системы к регенерации.

Одной из первых альтернативных трад-иционному репертуарному театру организационно-творческих форм стал репертуарный театр, объединяющий под одной крышей несколько трупп или режиссерских лабораторий. Сегодня таковыми являются, например, театр «Школа драматического искусства» в Москве, театры «Балтийский дом» и «Особняк» в Санкт-Петербурге. Данная организационно-правовая форма начала складываться в России в 1990-е гг. и к началу XXI в. доказала свою творческую плодотворность. Причины, обусловившие переход в новую для российского опыта форму театрального конгломерата, определялись эстетическими и этическими идеями каждого из театров.

Серьезные изменения в организационной модели репертуарного театра связаны с именем А. Васильева, создавшего в 1987 г. «Школу драматического искусства» (ШДИ), открывшуюся знаменитым спектаклем «Шесть персонажей в поисках автора» по пьесе Л. Пиранделло. Тематика и объем данной работы не представляют возможности углубляться в исследование важнейших для мирового театра опытов великого режиссера. Ограничимся лишь важной для дальнейшего анализа цитатой 3. Абдуллаевой о первом спектакле ШДИ: «После исповедального "Серсо" о сорокалетнем человеке <...> Васильев заготовил переход за пределы психологического театра и отрепетировал зазор между персонажем, назначенным актеру, и личностью актера» [1].
В ШдИ, с самого начала позиционирующей себя как оппозиция репертуарному театру, реализуется концепция театра как непрекращающегося процесса актерского обучения. Предложенная Васильевым экспериментальная модель состояла из слагаемых «лаборатория-школа-театр». Если в первый период существования ШДИ была сугубо авторским театром, то с 2006 г., после отъезда А. Васильева из России, вынужденная логика развития заявленной модели определила наличие различных творческих лабораторий в структуре одного театра. Сегодня в ШДИ функционируют лаборатории Д. Крымова, К. Мишина и И. Яцко.

Данная организационно-творческая форма явилась единственно возможной и для освоения продюсерских стратегий управления театром «Балтийский дом» как холдингом, включающим, помимо основной труппы, ряд международных фестивалей («Балтийский дом», «Встречи в Балтии», «Монокль») и несколько независимых экспериментальных коллективов. Театр «Особняк» представляет пример демократичного актерского театра, не только приглашающего различных режиссеров для работы с постоянной труппой, но и поддерживающего коллег по цеху, не имеющих стационарной площадки.

В интерпретации ШДИ, «Балтийского дома» и «Особняка» идея театра-дома для одной команды расширяется до многоквартирного жилища нескольких трупп или лабораторий. Однако если лаборатории московской ШДИ имеют специфическую поисковую направленность, не предполагающую ориентированности на кассовые сборы, то в случае санкт-петербургских театров в отношении «квартирантов» предполагается не только творческая, но и финансовая самостоятельность и ответственность.

Объединение под одной крышей по принципу конгломерата или нескольких разнородных художественных лабораторий оказалось не единственным вариантом развития современного репертуарного театра.

Одним из первых театров, созданных для экспериментов с современными текстами и поисков нового театрального языка, стал основанный в 1998 г. Центр драматургии и режиссуры под руководством А. Казанцева и М. Рощина (ЦДР). Его появление стало реакцией театральной среды на губительное отсутствие молодых сил режиссеров и драматургов. Изначально в штате ЦДР отсутствовали актерские ставки, его создатели видели новый театр как открытую и свободную территорию, где различные творческие команды смогут собираться для воплощения собственных идей.

К моменту создания ЦДР в Москве уже более десяти лет функционировал Театр Наций, в котором также не было собственной труппы. До 2007 г. театр 
выступал в качестве прокатной площадки, нацеленной на фестивальную деятельность и прием гастролей театров России и СНГ. С приходом в 2006 г. нового художественного руководителя Е. Миронова театр изменил принцип работы и существенно расширил фокус своего внимания: начал приглашать на проекты не только российских, но и зарубежных режиссеров, а спектакли, поставленные ими, составили постоянный репертуар.

В первой половине 2000-х гг. к ЦДР и Театру Наций добавилось еще несколько театров, в штатном расписании которых практически отсутствовали ставки артистического персонала. Среди них санкт-петербургский театр «Приют комедианта» (принявший данную организационно-творческую форму в 2000 г.), «Театр.doc» (основан в 2002 г. Е. Греминой и М. Угаровым), а также экспериментальный театральный центр новой драмы «Практика» (основан в 2005 г. Э. Бояковым). Одной из причин, повлиявших на распространение театров без труппы, была попытка разрешения проблемы обновляемости творческих коллективов в репертуарных театрах.

Спорным остается вопрос о принадлежности театров без труппы к модели репертуарного театра, тем более, что и создатели таких театров, и многие театроведы относят такие театры к проектной модели. Принимая во внимание доводы сторонников данной позиции, автор статьи все же склонен включить театры без труппы в типологию организационно-творческих форм репертуарной модели. Однако очевидно, что в рассматриваемом типе театра деюре отсутствует такой конституирующий признак репертуарного театра, как постоянная труппа, т. е. команда эстетических единомышленников, работающих в театре на постоянной основе и развивающихся в нем. Вследствие этого необходимо подробно аргументировать отнесение театров без труппы к репертуарной модели.

Основывая свои театры, Э. Бояков и М. Угаров стремились уйти от постоянной труппы как от одного из главных источников проблем современного российского театра. Приведем резкий отзыв Э. Боякова о театральной ситуации рубежа веков, характеризующий восприятие традиционной репертуарной модели новым радикальным поколением российских деятелей сцены: «К концу 1990-х стало понятно, что большинство репертуарных театров - это прибежище ностальгирующих, закомплексованных неудачников, которые не смогли адаптироваться к новым реалиям, боятся новой эпохи и не способны не то, что отражать эту реальность, но даже просто глядеть на нее. <...> Понимание невозможности творить в этих академических саркофагах привело креативных людей на новую территорию <...> Они формировали круг, из которого возник “Театр.doc”, a потом уже и театр “Практика” $[2]$.
Художественные руководители Театра Наций и «Приюта комедианта» Е. Миронов и В. Минков соответственно не делали подобных дерзких заявлений, хотя также выбрали данную организационнотворческую форму как более плодотворную.

Достоинства такой формы театра ее протагонисты видели в творческой мобильности, которая позволяет театру развиваться, не превращая его в замкнутый кружок. Также новые театры, работая исключительно по срочным контрактам, открывали двери для молодых режиссеров, драматургов, артистов, художников, которые были ориентированы на эксперимент и по тем или иным причинам не работали в репертуарных театрах.

Ставка на новые имена, остро необходимые театру в начале 2000-х гг., быстро дала результаты. В театрах без труппы получили возможность высказаться драматурги и режиссеры И. Вырыпаев, М. Гацалов, В. и М. Дурненковы, Н. Исаева, Ю. Клавдиев, Р. Маликов, В. Панков, П. Пряжко, К. Серебренников, М. Угаров и многие другие.

Однако с течением времени театры, позиционирующие себя как альтернатива репертуарным, начали проявлять в своей деятельности черты последних. В обновленных «Приюте комедианта», Театре Наций, ЦДР, «Театре.doc» и «Практике» стали складываться творческие команды, продолжающие совместные поиски от проекта к проекту.

Например, в «Театре.doc», существующем, по выражению П. Руднева, по принципу конфедерации ${ }^{1}$, за первые 5 лет его существования образовалась команда режиссеров, драматургов и артистов, объединенных идеей поиска нового театрального языка, а именно - языка театра повествования, вербатима, или документального театра. Благодаря не только максимально свободной форме театральной организации, но и фестивалям «Любимовка» и «Новая драма» вокруг «Театра.doc» сложилось сообщество экспериментаторов, в котором неформальное общение часто стимулировало коллективные творческие опыты. Многие совместные проекты были созданы М. Гацаловым, Е. Греминой, В. и М. Дурненковыми, Г. Жено, Ю. Клавдиевым, Р. Малико-

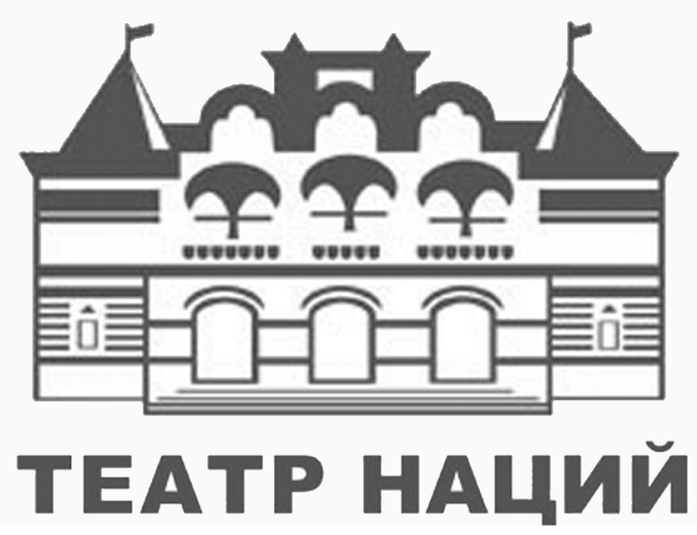




\section{TEATP.DOC TEATP, В КОТОРОМ НЕ ИГРАЮТ}

вым, А. Ребенок, М. Угаровым, А. Усердиным и др. В результате рождался протеический сплав творческих личностей, идей, инициатив, перетекавший из проекта в проект.

Театр «Практика», созданный на волне энергии «Театра.doc», в начале своего существования пошел по тому же пути освоения новой драматургии и поиска иного театрального языка. Не случайно манифест современной драматургии - «Кислород» И. Вырыпаева - был перенесен из «Театра. doc» в «Практику».

Со временем в «Практике» также начался процесс сплочения эстетических единомышленников. «Кислород» стал не просто важнейшим высказыванием театрального поколения, но и началом работы тандема И. Вырыпаева и В. Рыжакова. Вскоре к этому тандему прибавились актерские имена П. Агуреевой и С. Ивановой-Сергеевой. Результатом их сотворчества (в различных вариантах объединения) стали спектакли: «Июль», «Бытие № 2» и «Рыдания» - в «Практике», «Пять вечеров» - в «Мастерской П. Фоменко», «Иллюзии» - в МХТ им. А.П. Чехова, «Пьяные» - в Центре им. Вс. Мейерхольда.

Позже, в 2010-х гг., команда «Театра.doc» дополнилась именами Т. Баталова, М. Клещевой, Ю. Муравицкого, А. Палтай, А. Родионова и других, а во многих проектах «Практики» начали и продолжают работать А. Алябьев, К. Грушка, С. Землякова, В. Игнатов и М. Литвинова, К. Лиске и И. Сухорецкая. Вокруг данных театров образовывались постоянные творческие группы, состоящие из актеров, режиссеров, драматургов, а иногда и художников. Эти группы объединялись в процессе художественных поисков, шедших в определенной эстетической плоскости, на базе конкретной художественной платформы, т. е. той самой идеи, без которой невозможно существование репертуарного театра. Также данные театры имели лидеров, артикулирующих миссии и эстетические программы своих театральных организаций.

В 2012 г. С. Апфельбаум, рассуждая о тяготении новых театральных форм к репертуарной модели, зафиксировала подобный процесс и в театре

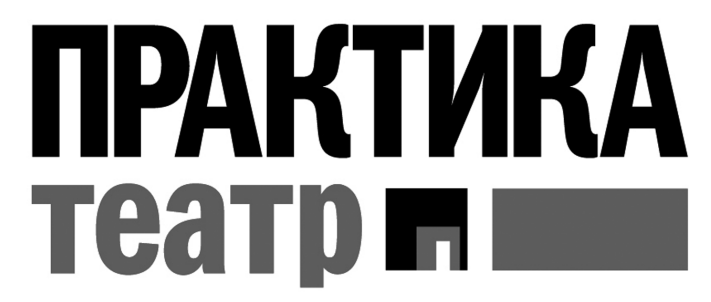

Наций: «Даже такая специфическая организация как Государственный театр Наций под руководством Евгения Миронова, который сознательно декларирует отказ от принципов репертуарной системы, в своей творческой деятельности также представляет собой коллектив единомышленников, собирающийся вокруг творческого лидера, и создающий собственный репертуар» [4]. Утверждение С. Апфельбаум подкрепляется словами самого Е. Миронова, произнесенными в том же году: «Почти шесть лет назад мы объявили программу сложносочиненного центра театральной культуры, театра без труппы <...>. Но сегодня у нас в спектаклях заняты уже более 150 артистов. И как бы мы ни хитрили, все-таки есть актеры, которые развиваются именно здесь, у нас, к нам уже привязаны» [5].

Тем не менее, стабильные творческие группы это еще не стабильная труппа. Обратимся к историческому примеру, а именно к образцовому репертуарному театру - Московскому Художественному. Исследуя его дореволюционный опыт, Ю. Орлов сделал важное открытие: постоянной в этом театре была не вся труппа, а лишь третья ее часть, т. е. всего 14 человек, и именно эта группа способствовала образованию мифа о стабильности знаменитого коллектива [6]. Следовательно, практика дореволюционного МХТ дает нам некоторое право говорить о возможности высокой (две трети труппы) и частой (ежегодной) обновляемости коллектива репертуарного театра.

Резюмируя, можно сказать, что, несмотря на формальное отсутствие постоянной труппы, в театрах, именующих себя по этой причине проектными, все же складывается творческий костяк - его составляют люди, объединенные общими художественными принципами, целями и задачами, которые сформулированы в миссии театра и транслируются его художественным лидером, а идейная программа выражается через репертуар. Таким образом, театры без труппы обретают основные черты репертуарных театров, вследствие чего автор относит их к репертуарной модели.

Манифестируемый антагонизм театров без труппы традиционному репертуарному театру был следствием не только проблемы обновляемости актерского состава. Новые театры оказались яростными противниками традиционной театральной эстетики. Их деятели стремились коренным образом пересмотреть все содержание современного им театра, чтобы найти героев, темы и формы их выражения, адекватные текущему моменту. Ощущалась характерная для смены столетий потребность в поиске альтернативных художественных концепций.

«Театр.doc» стал одним из первых российских театров, обратившихся к эстетике документа. По 
мнению М. Липовецкого, «интерес к документальности всегда связан с усталостью формы, с дискурсивным тупиком, когда, кажется, физически невозможно говорить на существующих в искусстве языках» [7, с. 86]. Интересно, что за протестом «Театра.doc» против «старых форм» стояло то же стремление выразить правду жизни, которое руководило создателями МХТ столетием ранее. Однако, работая с документальными текстами, режиссеры и актеры столкнулись с недостаточностью актерских методик XX в. для отражения того реализма, которым насыщен документ.

Документальный материал предполагал предельное сокращение дистанции не только между сценой и залом, но и между актером и его персонажем. На первый план выходил текст, именно он оказывался главным героем, но его специфическая - невыдуманная - фактура нуждалась в новой безошибочной интонации. Таким образом, документальность поставила перед художниками те же задачи, что и пьесы А.П. Чехова перед К.С. Станиславским и Вл.И. Немировичем-Данченко: требовался иной принцип актерского существования, и вскоре он был найден, а позже успешно применен к постановкам авторских (недокументальных) пьес современных и даже классических драматургов. Найденный принцип актерской игры театровед Е. Ковальская описывает следующим образом: «Исполняя текст, человек пребывает только тем, кем сам является; артист транслирует не героя и не его идеи, а свое чувство по отношению к идее» $[8$, с. 21$]$. Таким образом, документальный театр шел по тому же пути, по которому немногим ранее двигался один из реформаторов мирового театра А. Васильев, что указывает на верность и даже неизбежность выбранного направления поисков.

Стоит отметить, что обращение в начале 2000 -х гг. к документальной эстетике лишь в России стало своего рода точкой отсчета, в то время как европейский театр практиковал работу с различными документами в течение второй половины XX в. ${ }^{2}$ (например, «Дознание» П. Вайса) $)^{3}$. По мнению автора, в нашей стране сочетание опытов А. Васильева и документального театра стало той дорогой, по которой российский театр начал движение к эстетике перформативности, базирующейся на «концепции театра как события» [10, с. 65] (в противоположность «концепции театра как произведения» [10, с. 65]). Во-первых, в «Театре.doc», а затем и в ЦДР, и в «Практике» появился «неиграющий» актер, находящийся в «ноль-позиции» ${ }^{4}$, т. е. не реагирующий на события, происходящие с его персонажем, но имеющий собственный, личностный взгляд на них, что сближает такого актера с перформером. Во-вторых, в данных театрах, кроме спектаклей в традиционном понимании, стали появляться раз- личные интерактивные события, причем не только читки пьес и дискуссии после спектаклей.

Приведем описание одного из таких событий выпущенной в «Театре.doc» в 2007 г. постановки «Демократия.doc», «которая представляла собой интерактивную игру со зрителями в главных ролях. Спектакль вели два психолога, которые вместе с аудиторией выбирали определенное число игроков из зала. А каждый вышедший на сцену зритель выбирал для себя социальную роль. Роли менялись от спектакля к спектаклю и не были строго зафиксированы. Это могли быть “Президент”, “Россия”, “Терроризм”, “Телевидение”, “Коррупция" и т. д. Далее перед оставшимися в зрительном зале людьми разыгрывался спектакль - об “отношениях” между этими понятиями и героями. Психологи направляли представление, провоцировали, способствовали возникновению конфликтов. Каждый спектакль был уникален. Итак, вместо готового продукта процесс. Вместо завершенного произведения - изменяемая подвижная форма. Вместо режиссерского диктата - предложение вступить в диалог, реализуемое буквально» [12, с. 135].

Пример «Демократии.dос» коррелируется со спектаклем «Оскорбление публики», поставленным в 1966 г. во Франкфурте-на-Майне и описанным в книге Э. Фишер-Лихте «Эстетика перформативности». Э. Фишер-Лихте обращается к этой постановке, чтобы в очередной раз проиллюстрировать «ключевой момент этого парадигмального сдвига, а именно замену произведения (и, соответственно, установленных им взаимоотношений между субъектом и объектом, а также материальным и знаковым статусом) событием» [10, с. 39]. Немецкий театровед доказывает, что сложившаяся во второй половине XX в. ситуация «перформативного поворота» в искусстве обусловила необходимость разработки эстетики перформативности, которая, обозначив свое место в европейском театре, спустя 50 лет дала ростки и в российском театральном искусстве.

Итак, если снова обратиться к исторической ретроспективе и опыту MXT, то можно провести следующую параллель. Отечественному театру на рубеже XX-XXI, как и на рубеже XIX-XX вв., потребовалось переосмысление и принципиальное изменение существовавших организационнотворческих форм, чтобы совершить художественный переворот. При этом разница между МХT и новыми театрами без труппы заключается в масштабах произведенных переворотов. Если эстетические открытия МХТ явились новаторскими для мирового театрального искусства, то «Театр. doc» и его последователи двигались самостоятельно, но в фарватере поисков и открытий, которые были совершены европейским театром несколько десятилетий назад. 
Вместе с тем на данном этапе развития российского театра эксперименты с документальной эстетикой оказались необходимы. Принципы, найденные при работе с документом, оказались применимы и для театров, придерживающихся классической позиции. Так, например, С. Женовач обратился к материалу, полностью лишенному драматургического начала - к записным книжкам А.П. Чехова, выпустив спектакль «Записные книжки» в «Студии театрального искусства» (СТИ). Следующая премьера «Брат Иван Федорович» по Ф.М. Достоевскому продемонстрировала новую для СТИ подачу текста: режиссер обездвижил актеров, задав совершенно статичные мизансцены - так была обозначена безоговорочная текстовая доминанта. Текст выходил на первый план так же, как в документальных вербатимах.

Другим примером освоения традиционным репертуарным театром новых средств театральности может служить деятельность В. Рыжакова, много работавшего с текстами И. Вырыпаева в «Практике» и впоследствии апробировавшего найденные приемы на сцене «Мастерской П. Фоменко» в спектакле «Пять вечеров» с П. Агуреевой, И. Гординым, А. Колубковым и другими.

Примеры «Театра.doc» и «Практики» показывают, что в театрах без труппы также возможны развитие творческой индивидуальности и продуктивный поиск новых средств актерской выразительности. Однако в случае отсутствия штатной труппы стабильные творческие коллаборации, де-факто имеющие место в театрах без труппы, остаются в статусе проектов, что не мешает дальнейшему спрогнозированному продолжению сотрудничества, но нередко склоняет их участников к поиску параллельного более стабильного заработка.

Объяснима и концентрация таких театров в Москве - городе, лидирующем и по числу театров в России, и по количеству театральных вузов и актерских агентств.

О естественности образования данной организационно-творческой формы в условиях разнообразной театральной жизни города свидетельствует ее появление и в Санкт-Петербурге. В 2000 г., спустя 2 года после учреждения в Москве ЦДР, в северной столице в форму театра без труппы перешел «Приют комедианта». Санкт-Петербург также является одним из самых театральных городов России. Данное обстоятельство указывает на два момента. Распространение новой модели, вопервых, связано с развитой городской театральной инфраструктурой, а во-вторых, является ее логическим продолжением и, возможно, необходимым расширением.

Очевидно, что театр без труппы не сможет функционировать в условиях отсутствия широкого рынка артистического труда, т. е. в большинстве россий- ских городов. Однако даже в Москве, где кадровые ресурсы неограничены, у театров без труппы возникают проблемы с прокатом репертуара. Отсутствие собственной труппы усложняет процесс эксплуатации репертуара: театр вынужден планировать прокат, ориентируясь в первую очередь на график артистов, многие из которых состоят в штатах театров, где имеют приоритетную занятость.

Заметим, что в европейской практике подобная форма театра - где актеры не состоят в постоянном штате, но регулярно работают с определенными режиссерами в проектах, из которых складывается репертуар, - относится к репертуарной модели.

Проанализировав структуру репертуарных театров Германии, О. Федянина приходит к выводу о разнообразии видов актерских трудовых договоров с немецкими театральными организациями [13, с. 77-78]. Это может быть как зачисление в штат на постоянной основе, так и договор о занятости в конкретном проекте, или же срочный трудовой договор. При этом распространены случаи, когда актеры в течение длительного периода работают с определенным режиссером, оставаясь вне штата театра. Различные примеры репертуарного театра - как с постоянной труппой, так и без нее - описывает и А. Бартошевич, рассказывая о формах организации репертуарного театра в Британии [14].

Европейские артисты часто предпочитают краткосрочные договоры зачислению в штат из-за строгих обязательств, налагаемых на служащих в постоянной труппе театра. «Оказавшись в штате, актер становится кем-то наподобие медицинского работника, которому не позволено отключать телефон даже ночью, во время сна» [13, с. 77].

В России, как известно, ситуация обратная. Отечественный опыт свидетельствует о более мягком отношении театров к штатным артистам труппы, а зачисление в штат предполагает хотя и скромную (в большинстве случаев), но стабильную зарплату. Говоря о Германии, О. Федянина также отмечает, что «если за три месяца до истечения срока человека не предупредили о том, что контракт будет расторгнут, значит, он автоматически продлевается на следующий сезон. Еще год никто не имеет права уволить сотрудника» $[13$, с. 77$]$. Российская же действительность зачастую непредсказуема, вследствие чего большинство российских актеров больше стремятся состоять в штате театра, чем работать по краткосрочным договорам и контрактам на конкретную постановку.

Итак, в 2000-е гг. российская театральная практика приобретает тенденцию к многообразию организационно-творческих форм, которые, несмотря на декларируемый отказ от модели репертуарного театра, все же тяготеют к последней. 
Одновременно сосуществуя в художественнокультурном поле, репертуарные театры традиционной и альтернативной формы влияют друг на друга - как в творческом, так и в организационном аспектах.

В репертуарных театрах альтернативных организационно-творческих форм происходит поиск, а затем апробация нового сценического языка и методов актерского существования. Образующиеся в новых театрах команды, ощущая себя оппозицией традиционности, стремятся к новизне и усваивают ее намного легче, чем устоявшиеся коллективы традиционных репертуарных театров. Тем не менее, традиционные театры приглашают режиссеров-экспериментаторов на постановки, чем запускают процесс творческой диффузии. Таким образом, результаты, полученные в театрах альтернативных форм, осваиваются традиционными репертуарными театрами, которые на новом уровне продолжают творческие поиски.

Опыты репертуарных театров альтернативных организационно-творческих форм сближают российское драматическое искусство с европейским. Так, например, театр-фестиваль «Балтийский дом» проводит три международных фестиваля и выпускает ряд проектов в ко-продукции с театрами Европы. Исследования документальных текстов приводят к появлению на российских подмостках интерактивных спектаклей«событий» в «Театре.doc», в которых зрители, выступая в качестве актеров, получают уникальный эмоциональный и этический опыт, что является важнейшим признаком перформативного театра, а поиски в театре А. Васильева имеют непреходящее значение для истории театрального искусства.

Однако широкое распространение театров альтернативных форм в российских регионах вряд ли возможно на данном этапе развития театральной системы по ряду причин. Для нового способа ведения театрального дела необходимы коренные изменения в инфраструктуре: создание эффективно функционирующей театральной биржи всероссийского масштаба, возможность свободной миграции творческих кадров, юридическая и финансовая защищенность актеров, не состоящих в штате театральных организаций, и, конечно, публика, заинтересованная в самых неожиданных художественных экспериментах.

\section{Примечания}

1 «Актерско-режиссерские команды собираются здесь на один спектакль и полностью ответственны за весь про- цесс от начала репетиций до проката, включая уборку помещения, рекламу и администрирование» [3].

2 Опыт английского театра Royal Court способствовал сближению российского театра с данной эстетикой.

3 Что, по мнению Х.-Т. Лемана, «отчасти указывает своим вектором за пределы традиции драматического театра» [9, с. 89].

4 Согласно термину, предложенному М. Угаровым [11].

\section{Список источников}

1. Абдуллаева 3. Васильев: система [Электронный ресурс] // Театр. URL: http://oteatre.info/vasilyevsistema/ (дата обращения: 25.02.2016).

2. Бояков Э. Слова берутся из реальности [Электронный ресурс] // DEI / Deillusionist. URL: http://www.deiz. ru/data/10/07.html (дата обращения: 25.02.2016).

3. Руднев П. Выживание «Театра.doc» [Электронный ресурс] // Взгляд. URL: http://vz.ru/columns/ 2006/5/24/34782.html (дата обращения: 25.02.2016).

4. Апфельбаум С.M. Современный российский театр: состояние и перспективы // Культура России. Москва : ГИВЦ Минкультуры России, 2012. Т. 2012 : Актуальные задачи духовного возрождения России. С. 62-73.

5. Миронов Е. Шекспиры на контрактной основе [Электронный ресурс] // Российская газета. URL: http:// www.rg.ru/2012/10/08/mironov.html (дата обращения: 25.02.2016).

6. Орлов Ю.М. Московский Художественный Театр. Новаторство и традиции в организации творческого процесса: автореф. дис. ... д-р искусствоведения. Ленинград, 1989.36 с.

7. Липовецкий М. Иллюзия документальности и другие иллюзии // Театр. 2015. Вып. 19. С. 84-89.

8. Ковальская Е. Движение «Солидарность»: на открытие Театра.doc // Театр. 2015. Вып. 19. С. 16-25.

9. Леман Х.-T. Постдраматический театр. Москва : ABCdesign, 2013. 312 c.

10. Фишер-Лихте Э. Эстетика перформативности. Москва : Канон+, 2015. 376 с.

11. Хакимов Т. Обнуление ноль-позиции [Электронный ресурс] // Искусство кино. 2013. Вып. 5. URL: http:// kinoart.ru/archive/2013/05/obnulenie-nol-pozitsii (дата обращения: 25.02.2016).

12. Болотян И. «Док» и «Догма»: теория и практика // Театр. 2015. Вып. 19. С. 130-139.

13. Федянина О. Организационные формы и структура современного немецкого театра // Proscaenium. Boпросы театра. Москва : ГИИ, 2013. Вып. 13. С. 76-82.

14. Бартошевич А. Как это делается в Британии // Рroscaenium. Вопросы театра. Москва : ГИИ, 2013. Вып. 13. С. 83-84. 


\section{UNTYPICAL ORGANIZATIONAL AND CREATIVE FORMS OF THE RUSSIAN REPERTORY THEATRE IN THE 2000s}

\section{NADEZHDA L. FROLOVA,}

Russian University of Theatre Arts (GITIS), 6 Maly Kislovsky Lane, Moscow, 125009, Russia

E-mail: frolova.gitis@gmail.com

\begin{abstract}
The article considers those organizational and creative forms of repertory theatres which arose at the turn of the 21st century and are not characteristic for the Russian theatrical practice. They are the theatre conglomerates uniting several theatre groups of various artistic styles as well as some theatres without any stock company, which, while claiming to be project-type ones, nevertheless tend to be repertoire-based. The article argues that the theatres without any stock company should be classified as repertory theatres, which may provide the academic novelty of this work.

The process of functioning of the nontraditional organizational and creative forms is examined in correlation with the development of the modern theatrical art language, which makes the article really up-to-date. The article is based upon the materials of such Moscow and Saint-Petersburg theatres as: the Baltic House Festival Theatre, the Osobnyak Theatre, the Praktika Theatre, the Priyut Komedianta Theatre, the Theatre.doc, the Theatre of $\mathrm{Na}$ tions, the Centre of Dramaturgy and Directing, and the Dramatic Art School.

The article also analyzes the interaction between traditional and alternative forms of the repertory theatre activity and compares them with foreign repertory models.
\end{abstract}

Key words: A. Vasilyev, documentality, the Moscow Art Theatre, performativity, stock company, project theatre, repertory theatre, theatres without a stock company.

Citation: Frolova N.L. Untypical Organizational and Creative Forms of the Russian Repertory Theatre in the 2000s, Observatory of Culture, 2016, vol. 13, no. 3, pp. $321-328$.

\section{References}

1. Abdullaeva Z. Vasilyev: Sistema [Vasiliev: System], Teatr [Theatre]. Available at: http://oteatre.info/vasilyev-sistema/ (accessed 25.02.2016).
2. Boyakov E. Slova berutsya iz realnosti [The Words are From Reality], DEI / Deillusionist. Available at: http:// www.deiz.ru/data/10/07.html (accessed 25.02.2016).

3. Rudnev P. Vizhivanie "Teatra.doc" [Survive of Teatr.doc], Vzglyad [The Business Newspaper "Vzglyad"]. Available at: http://vz.ru/columns/2006/5/24/34782.html (accessed 25.02.2016).

4. Apfelbaum S.M. Sovremennij rossijskij teatr: sostoyanie i perspektivi [Modern Russian Theatre: Condition and Perspectives], Kul'tura Rossii [Culture of Russia]. Moscow GIVTS Minkul'turi Rossii Publ., 2012. vol. 2012 (Aktual'nye zadachi dukhovnogo vozrozhdeniya Rossii [Actual Tasks of Spiritual Revival in Russia]), pp. 62-73.

5. Mironov E. Shekspiri na kontraktnoi osnove [Shakespeares at the Contract's Base], Rossiyskaya Gazeta. Available at: http://www.rg.ru/2012/10/08/mironov.html (accessed 25.02.2016).

6. Orlov Y.M. Moskovskii Khudozhestvennii teatr. Novatorstvo i traditsii v organizatsii tvorcheskogo protsessa [Moscow Art Theatre. Innovation and Tradition in Organization of the Creative Process]. Leningrad Publ., 1989, 36 p.

7. Lipovetskii M. Illuziya dokumental'nosti I drugie illuzii [The Illusion of Documentary and Other Illusions], Teatr [Theatre], 2015, issue 19, pp. 84-89.

8. Koval'skaya E. Dvizhenie "Solidarnost'": na otkritie Teatra [Movement "Solidarity": At the Opening of the Theatre], Teatr [Theatre], 2015, issue 19, pp. 16-25.

9. Leman H.-T. Postdramaticheskii teatr [Postdramatic Theatre]. Moscow, ABCdesign Publ., 2013, 312 p.

10. Fisher-Lichte E. Estetika performativnosti [Performative Aesthetics]. Moscow, Kanon+ Publ., 2015, 376 p.

11. Khakimov T. Obnulenie nol'-pozitsii [Reset of Zero- Position], Iskusstvo kino [Art of the Cinema], 2013, issue 5. Available at: http://kinoart.ru/archive/2013/05/obnulenie-nol-pozitsii (accessed 25.02.2016).

12. Bolotiyan I. "Dok" i "Dogma": teoriya i praktika ["Dock" and "Dogma": Theory and Practice], Teatr [Theatre], 2015, issue 19, pp. 130-139.

13. Fedyanina O. Organizatsionnie formi i struktura sovremennogo nemetskogo teatra [Organisational Formes and the Structure of Modern German Theatre], Voprosi teatra. Proscaenium [Problems of the theatre. Proscaenium]. Moscow, GII Publ., 2013, issue 13, pp. 76-82.

14. Bartoshevich A. Kak eto delaetsya v Britanii [How it's done in Britain], Voprosi teatra. Proscaenium [Problems of the theatre. Proscaenium]. Moscow, GII Publ., 2013, issue 13, pp. 83-84. 